\title{
The Sp1 transcription factor is essential for the expression of gliostatin/thymidine phosphorylase in rheumatoid fibroblast-like synoviocytes
}

Kenji Ikuta ${ }^{1}$, Yuko Waguri-Nagaya ${ }^{1 *}$, Kae Kikuchi $^{1}$, Takaya Yamagami', Masahiro Nozaki ${ }^{1}$, Mineyoshi Aoyama $^{2}$, Kiyofumi Asai ${ }^{2}$ and Takanobu Otsuka'

\begin{abstract}
Introduction: Gliostatin/thymidine phosphorylase (GLS/TP) has angiogenic and arthritogenic activities, and aberrant GLS production has been observed in the active synovial membranes of rheumatoid arthritis (RA) patients. The human GLS gene promoter contains at least seven consensus binding sites for the DNA binding protein Sp1. Here we examined whether Sp1 is necessary for GLS production in RA. We also studied the effects of the Sp1 inhibitor mithramycin on GLS production in RA fibroblast-like synoviocytes (FLSs).

Methods: FLSs from RA patients were treated with specific inhibitors. The gene and protein expression of GLS were studied using the quantitative reverse-transcription polymerase chain reaction (qRT-PCR) and an enzyme immunoassay. Intracellular signalling pathway activation was determined by western blotting analysis, a luciferase assay, a chromatin immunoprecipitation (ChIP) assay and a small interfering RNA (siRNA) transfection.

Results: The luciferase and ChIP assays showed that Sp1 binding sites in the GLS promoter were essential for GLS messenger RNA (mRNA) expression. GLS production was suppressed in FLSs by siRNA against Sp1 transfection. Mithramycin decreased GLS promoter activity, mRNA and protein expression in FLSs. Tumour necrosis factor- $\alpha$ (TNF- $\alpha$ ) significantly increased GLS expression in RA FLSs; this effect was reduced by pre-treatment with cycloheximide and mithramycin.

Conclusions: Pretreatment of mithramycin and Sp1 silencing resulted in a significant suppression of GLS production in TNF- $\alpha$-stimulated FLSs compared to controls. GLS gene expression enhanced by TNF- $\alpha$ was partly mediated through Sp1. As physiological concentrations of mithramycin can regulate GLS production in RA, mithramycin is a promising candidate for anti-rheumatic therapy.
\end{abstract}

\section{Introduction}

Many components of the immune system contribute to the development and progression of rheumatoid arthritis (RA), and angiogenesis is considered a critical step in its initiation and progression. Levels of inflammatory cytokines such as tumor necrosis factor-alpha (TNF- $\alpha$ ) and interleukin-1-beta (IL-1 $\beta$ ) and IL-6 [1-3] are increased in arthritic joints, whereas high levels of angiogenic factors such as vascular endothelial growth factor (VEGF) $[4,5]$ and gliostatin (GLS) $[6,7]$ have been reported in

\footnotetext{
* Correspondence: waguri@med.nagoya-cu.ac.jp

'Department of Orthopedic Surgery, Nagoya City University Graduate School of Medical Sciences, 1 Kawasumi, Mizuho-cho, MuzuhoMizuho-ku, Nagoya, 467-8601, Japan

Full list of author information is available at the end of the article
}

synovial fluid and sera from patients with RA. For this reason, the past decade has seen the development of biological treatments for RA, such as TNF- $\alpha$ inhibitors.

GLS is thought to be similar to thymidine phosphorylase (TP) and platelet-derived endothelial cell growth factor (PD-ECGF) [8] and induces angiogenesis through the proliferation and chemotactic migration of endothelial cells [9-11]. It also inhibits the growth of glial cells [12], promotes glial cell differentiation, and has neurotrophic effects on cortical neurons [13]. GLS production by cultured RA fibroblast-like synoviocytes (FLSs) was shown to be enhanced by TNF- $\alpha$ [14], IL-1 $\beta$ [15], and GLS itself [16]. GLS was also found to induce VEGF expression in FLSs [14], and we reported that direct injection of GLS

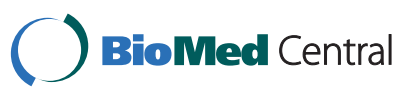

(C) 2011 Ikuta et al.; licensee BioMed Central Ltd. This is an open access article distributed under the terms of the Creative Commons Attribution License (http://creativecommons.org/licenses/by/2.0), which permits unrestricted use, distribution, and reproduction in any medium, provided the original work is properly cited. 
into rabbit knees led to pronounced RA-like synovitis [17]. Inhibition of GLS is therefore regarded as an important approach in reducing damage to RA tissues.

Analysis of the TP promoter region revealed several potential zinc finger-type transcription factor Sp1-binding sites, including those in numerous housekeeping and inducible genes [18], in the interferon-stimulated response element (ISRE), and in the gamma-activated sequence [19]. In the present study, we used a luciferase assay and a small interfering RNA (siRNA) against $\mathrm{Sp} 1$ to show that the $\mathrm{Sp} 1$ box is essential for GLS production. We also used the inhibitor mithramycin to demonstrate the effect of Sp1-binding inhibition on GLS expression. Mithramycin is an aureolic acid anti-neoplastic antibiotic used for treating cancer-related hypercalcemia, leukemia [20], and testicular cancer [21] and prevents Sp1 from binding to its cognate site in DNA by modifying CG sequences [22]. Here, we show that mithramycin potently suppresses GLS induction through the transduction of Sp1 in RA FLSs.

\section{Materials and methods}

\section{Preparation of human fibroblast-like synoviocytes}

This study was approved by the ethics committee of Nagoya City University (Nagoya City, Japan). Before participation, informed consent was obtained from all subjects in accordance with the Declaration of Helsinki. FLSs were cultured from the synovial tissues of 10 patients who had RA, who were undergoing total knee arthroplasty, and who met the American Rheumatism Association 1987 revised criteria for the classification of RA [23], as previously described [24-26]. The clinical characteristics of these patients are shown in Table 1. FLSs were maintained in Dulbecco's modified Eagle's medium supplemented

Table 1 Clinical characteristics of patients

\begin{tabular}{lc}
\hline Characteristic & $\mathbf{n}=10$ \\
\hline Gender, female/male & $7 / 3$ \\
Age in years, range (mean) & $48-74(65.0)$ \\
Disease duration in years, range (mean) & $1-18(10.6)$ \\
CRP in mg/dL, range (mean) & $0.05-3.34(0.66)$ \\
ESR in mm/hour, range (mean) & $1-83(20.8)$ \\
Rheumatoid factor, positive/negative & $9 / 1$ \\
Anti-CCP antibody in U/mL, range (mean) & $0.6-100(37.8)$ \\
MMP-3 in ng/mL, range (mean) & $38.9-525.7(222)$ \\
Steinbrocker stage, I/II/II/IV & $0 / 5 / 3 / 2$ \\
Patients using DMARDs and biologics & \\
$\quad$ Methotrexate & 7 \\
Infliximab & 1 \\
Etanercept & 2 \\
FK506 & 2 \\
Patients using oral steroids & 5
\end{tabular}

Anti-CCP, anti-cyclic citrullinated peptide; CRP, C-reactive protein; DMARD, disease-modifying anti-rheumatic drug; ESR, erythrocyte sedimentation rate; MMP-3, matrix metalloproteinase-3. with penicillin (100 units per $\mathrm{mL})$, streptomycin $(100 \mu \mathrm{g} /$ $\mathrm{mL}$ ), and $10 \%$ fetal bovine serum at $37^{\circ} \mathrm{C}$ in a $5 \% \mathrm{CO}_{2}$ atmosphere. The cultures were found to be completely free of lymphoid and monocytic cells. Cells were allowed to adhere overnight, and then non-adherent cells were removed and adherent FLSs were split at a 1:3 ratio when they reached $70 \%$ to $80 \%$ confluency. FLSs were used between passages 3 and 9, during which time they were a homogeneous population of cells.

\section{Luciferase assay}

The 1,243-base pair (bp) GLS/TP promoter fragment was a kind gift from Mayumi Ono (Department of Pharmaceutical Oncology, Kyushu University, Fukuoka, Japan) [19]. The fragment was cloned into luciferase gene Basic Vector 2 (NIPPON GENE CO., LTD, Tokyo, Japan) and digested with XhoI and HindIII. This reporter construct was designated pTP-Luc1. To prepare other deletion constructs, pTP-Luc1 was digested with different restriction enzymes, including XhoI, StuI, SacI, and KpnI. Both 5' overhangs and 3' overhangs of the digested product were blunted by T4 DNA polymerase (Takara Bio Inc., Otsu, Japan) and self-ligated by T4 DNA ligase (Takara Bio Inc.) to produce pGLS/TP I, pGLS/TP II, and pGLS/TP III (Figure 1).

FLSs were seeded into a 48 -well culture plate $\left(5 \times 10^{3}\right.$ cells per well) and incubated at $37^{\circ} \mathrm{C}$ in a humidified atmosphere of $5 \% \mathrm{CO}_{2} /$ air for 1 week. They were then cotransfected with luciferase reporter vector (400 ng/well) and pRL-SV40 internal control construct (10 ng/well) (Promega Corporation, Madison, WI, USA) by using Lipofectamine $^{\mathrm{TM}}$ LTX $(0.5 \mu \mathrm{L} /$ well $)$ and Plus ${ }^{\mathrm{TM}}$ Reagent $(0.5 \mu \mathrm{L} /$ well) (Invitrogen Corporation, Life Technologies Corporation, Carlsbad, CA, USA). The medium was replaced after 12 hours, and FLSs were treated with 100 or $300 \mathrm{nM}$ mithramycin (Sigma-Aldrich, St. Louis, MO, USA) for 24 hours. Cells were harvested by using passive lysis buffer ( $65 \mu \mathrm{L} /$ well), and the luciferase activity was measured by using a Dual-Luciferase Assay System (Promega Corporation) and normalized to the internal control.

\section{Chromatin immunoprecipitation assays}

Chromatin immunoprecipitation (ChIP) assays were performed by using ChIP-ITTM Express kits (Active Motif, Carlsbad, CA, USA) in accordance with a reported protocol [27] with minor modifications. In brief, $1.0 \times 10^{6} \mathrm{FLSs}$ cells from $60-\mathrm{mm}$ dishes were treated with or without $300 \mathrm{nM}$ mithramycin for 24 hours and then harvested. Cells were cross-linked by formaldehyde ( $1 \%$ final concentration) and incubated at room temperature for $10 \mathrm{~min}$ utes. Cells were then washed with ice-cold phosphatebuffered saline (PBS) containing protease inhibitors, and the fixation reaction was stopped by adding $10 \mathrm{~mL}$ of Glycine Stop-Fix Solution (Active Motif). Samples were lysed for 30 minutes in lysis buffer on ice, and the chromatin 


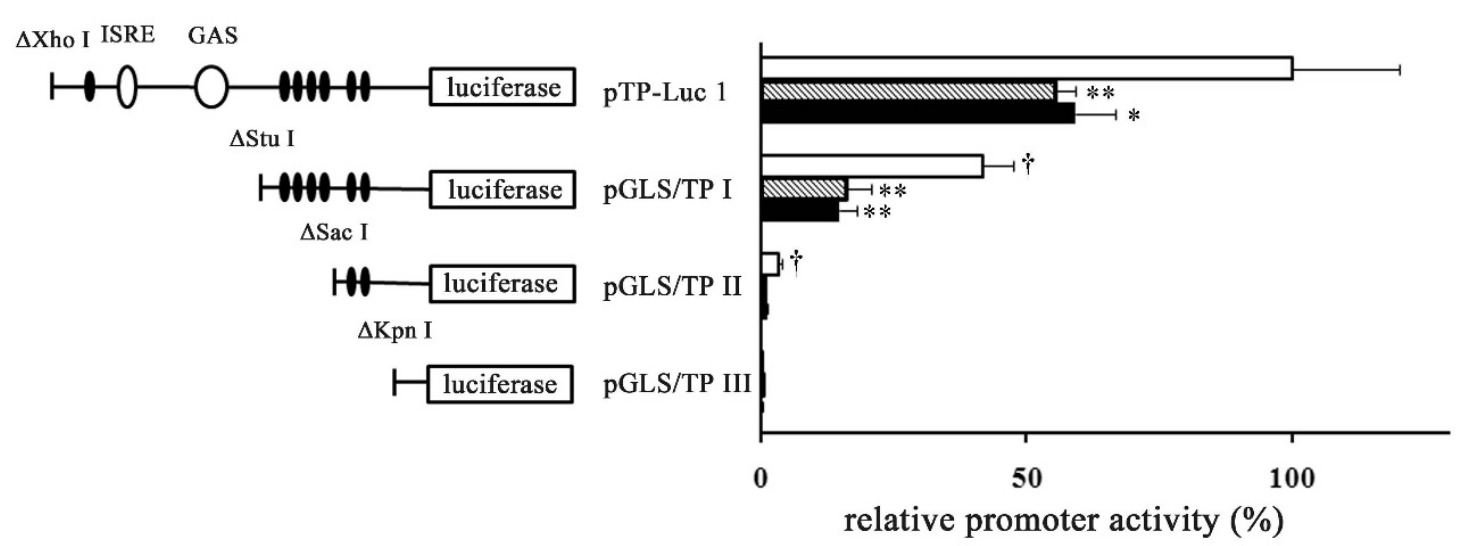

Figure 1 Effects of mithramycin on gliostatin/thymidine phosphorylase (GLS/TP) promoter activity based on deletion constructs Closed ovals indicate Sp1-binding sites. Open ovals indicate interferon-stimulated response element (ISRE) and gamma-activated sequence (GAS) sequences. Fibroblast-like synoviocytes were transiently transfected with deletion constructs and then incubated with mithramycin (100 nM, shaded column, or 300 nM, closed column) for 24 hours. Control cells were incubated without mithramycin (open column). Data were normalized by measuring the luminescent reaction of the internal control. Results are presented as mean \pm standard error of the mean of five determinations. Statistical significance was calculated by using the Mann-Whitney $U$ test: compared with samples without mithramycin ${ }^{*} P<0.05$, **P 0.01 ; compared with samples with PTP-Luc1 without mithramycin ${ }^{\dagger} P<0.01$.

was sheared by sonicating 20 times for 40 seconds each at maximum power with an ultrasonic processor, including 30 seconds of cooling on ice between each pulse (Misonix, Inc., Farmingdale, NY, USA). Cross-linked and released chromatin fractions were immunoprecipitated with magnetic beads, Sp1 antibodies, and non-specific IgG (rabbit) on a rolling shaker overnight at $4^{\circ} \mathrm{C}$. Cross-linking of the immunoprecipitates containing fragmented DNA was chemically reversed, and the polymerase chain reaction (PCR) was performed with MESA GREEN qPCR MasterMix Plus for SYBR Assay I Low ROX (Eurogentec, San Diego, CA, USA). The PCR primers used for amplifying promoters containing the Sp1-binding site furthest upstream were 5'AACTGTGGGCCTTCCCACTC-3' and 5'-TGCTGAGGT CCTCGAAGAAAC-3', which produced a 227-bp fragment (Figure 2a).

\section{Western blot analysis for Sp1}

FLSs were incubated in 60-mm dishes with $1 \mathrm{ng} / \mathrm{mL}$ TNF$\alpha$ (R\&D Systems, Minneapolis, MN, USA) in the presence or absence of mithramycin. To prepare nuclear extracts, cells were rinsed in ice-cold PBS and lysed in $10 \mathrm{mM}$ Tris$\mathrm{HCl}$ (pH 7.5), $1 \mathrm{mM}$ ethylenediaminetetraacetic acid (EDTA), $0.5 \%$ Nonidet P-40, and a protease inhibitor cocktail (Sigma-Aldrich) for 10 minutes at $4^{\circ} \mathrm{C}$. Cell lysates were centrifuged at 20,000 $\mathrm{g}$ for 10 minutes at $4^{\circ} \mathrm{C}$ to separate the cytoplasmic fraction (supernatant). Insoluble materials were dissolved in sodium dodecyl sulphate sample buffer to collect the nuclear extracts. After measuring
A

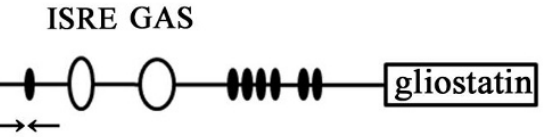

B

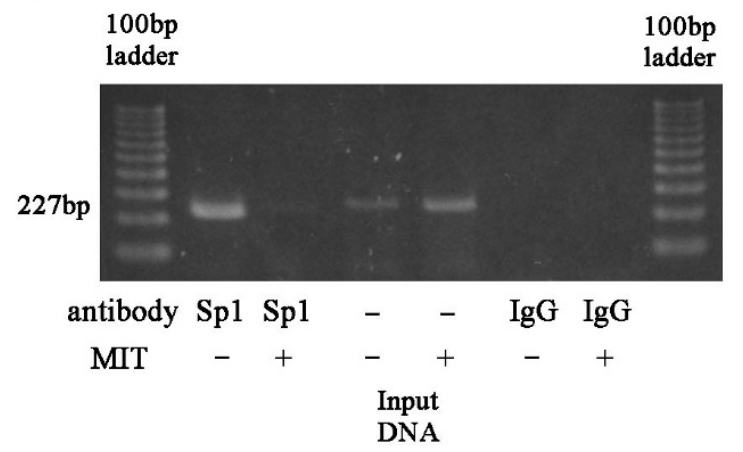

Figure 2 Effect of mithramycin on Sp1 binding with chromatin immunoprecipitation (ChIP) assays. Closed ovals indicate Sp1binding sites. Open ovals indicate interferon-stimulated response element (ISRE) and gamma-activated sequence (GAS) sequences. Arrows indicate the polymerase chain reaction primers used for amplifying gliostatin/thymidine phosphorylase (GLS/TP) promoter containing the Sp1-binding site furthest upstream (A). Confluent fibroblast-like synoviocytes were incubated in the presence or absence of $300 \mathrm{nM}$ mithramycin for 24 hours. Sp1 binding to the furthest upstream Sp1-binding site within the GLS/TP promoter was detected by ChIP assays. This binding was suppressed by treatment with mithramycin (B). Similar observations were obtained at least three times. bp, base pairs; MIT, mithramycin. 
the protein concentration, samples $(20 \mu \mathrm{g}$ of total protein/ lane) were loaded and separated by electrophoresis on a 7.5\% polyacrylamide gel (Bio-Rad Laboratories, Hercules, CA, USA) and then transferred to a polyvinylidene difluoride membrane (Immobilin-P; EMD Millipore, Billerica, MA, USA). The blots were blocked for 60 minutes with $5 \%$ non-fat dry milk in Tris-buffered saline containing $0.1 \%$ Tween 20 (TBS-T) and then incubated with an antiSp1 antibody (1:1,000; Cell Signaling Technology, Inc., Danvers, MA, USA), anti-lamin C (1:1,000; ImmuQuest Ltd, Seamer, North Yorkshire, UK), and anti- $\alpha$-tubulin antibody (1:1,000; Cell Signaling Technology, Inc.) as loading controls in TBS-T for 2 hours at room temperature. After three washes with TBS-T, membranes were incubated with appropriate horseradish peroxidase-conjugated secondary antibodies in TBS-T (1:3,000; GE Healthcare, Little Chalfont, Buckinghamshire, UK) for 1 hour at room temperature and washed three times with TBS-T. Protein bands were detected by using the ECL Plus Western Blotting Detection System (GE Healthcare) and then quantified with a densitometric scanner by using ImageJ software [28].

\section{Reverse transcription-polymerase chain reaction assay}

Expression of the GLS gene was assessed by using reverse transcription-PCR (RT-PCR). Total RNA was isolated by using TRIzol reagent (Invitrogen Corporation), and RT was carried out by using random primers and Ready-ToGo You-Prime First-Strand Beads (GE Healthcare). The resultant $\mathrm{CDNA}$ was subjected to real-time PCR by using a 7500 Fast Real-time PCR System (Life Technologies Corporation) with MESA GREEN qPCR MasterMix Plus for SYBR Assay I Low ROX (Eurogentec) and primers. The PCR conditions were an initial denaturation at $95^{\circ} \mathrm{C}$ for 10 minutes, followed by 40 cycles at $95^{\circ} \mathrm{C}$ for 5 seconds and $60^{\circ} \mathrm{C}$ for 1 minute. The relative quantification value of GLS was normalized to an endogenous control, $\beta$-actin, after confirming that the GLS and $\beta$-actin cDNAs were amplified with the same efficiency. The primers were as follows: GLS, 5'-ACAGGAGGCACCTTGGATAA-3' and 5'-CCGAACTTAACGTCCACCAC-3' (272 bp), and $\beta$ actin, 5'-GACCTGACTGACTACCTCAT-3' and 5'TCGTCATACTCCTGCTTGCT-3' (542 bp).

\section{RNA interference}

Sp1 Stealth siRNAs and negative control siRNA were purchased from Invitrogen Corporation. The following Sp1 siRNA oligos were used: sense sequence 5'-GACAGGUCAGUUGGCAGACUCUACA-3' and anti-sense sequence 5'-UGUAGAGUCUGCCAACUGACCUGUC-3'. FLSs were transfected with the indicated combinations of siRNA against $\mathrm{Sp} 1$ or negative control siRNA at a final concentration of $20 \mathrm{nM}$ by using Lipofectamine
RNAiMAX transfection reagent (Invitrogen Corporation) in accordance with the recommendations of the manufacturer. FLSs were harvested for Western blotting 48 hours after transfection. FLSs were incubated for 24 hours after transfection and further incubated with $1 \mathrm{ng} / \mathrm{mL}$ TNF- $\alpha$ for 24 hours and harvested for RT-PCR.

\section{Enzyme immunoassay for gliostatin}

GLS was measured by using an enzyme immunoassay system, as described by Hirano and colleagues [29]. Polyclonal antibodies on the solid phase were obtained by immunizing New Zealand albino rabbits with $40 \mu \mathrm{g}$ of purified natural human GLS, and the monoclonal antibody was used with the $\beta$-galactosidase-labeled secondary antibody. The detection limit of this assay was $150 \mathrm{pg} / \mathrm{mL}$, and no significant cross-reactivity or interference was observed. The GLS concentration in cultured FLSs was normalized to the protein content, as measured by using a Pierce BCA protein assay kit (Thermo Fisher Scientific, Waltham, MA, USA).

\section{Immunocytochemistry}

Confluent FLSs in chambered slides coated with BD Matrigel Matrix (BD Biosciences, Franklin Lakes, NJ, USA) were fixed for 30 minutes in $3 \%$ paraformaldehyde, permeabilized with $0.2 \%$ Triton X-100 for 5 minutes, washed with PBS, and blocked for 60 minutes at room temperature with blocking solution comprising $3 \%$ bovine serum albumin and $0.1 \%$ glycine in PBS. After washing, cells were labeled overnight at $4{ }^{\circ} \mathrm{C}$ with the primary antibody (1:1,000 anti-TP/GLS antibody; a gift from Chugai Pharmaceutical Co., Ltd., Tokyo, Japan). Cells were washed and labeled with an Alexa Flour 594-labeled (red) goat anti-mouse IgG (1:1,000; Molecular Probes Inc., now part of Invitrogen Corporation) secondary antibody. After washing, sections were mounted on glass slides containing ProLong Gold Antifade with 4',6-diamidino-2-phenylindole (DAPI) (Invitrogen Corporation). Stained cells were visualized by using an AX70 fluorescence microscope (Olympus, Tokyo, Japan). Total red intensity of immunostaining in nine random fields was quantified by ImageJ. The numbers of cells were counted in the fields. Data were presented as mean of intensity per cell.

\section{Statistical analysis}

All data were entered into an electronic database and analyzed by using GraphPad Prism 4 (GraphPad Software, Inc., San Diego, CA, USA). Data are expressed as the mean \pm standard error of the mean unless otherwise stated. The statistical significance of the differences was examined by using the Mann-Whitney $U$ test. In all cases, $P$ values of less than 0.05 were considered to be statistically significant. 


\section{Results}

Mithramycin inhibited gliostatin gene expression

We prepared three deletion constructs of the GLS/TP promoter and fused them to the reporter luciferase plasmid (Figure 1) to investigate whether mithramycin inhibited GLS/TP promoter activity. The promoter activity was expressed relative to the internal control. Treatment with mithramycin inhibited the promoter activity in RA FLSs transfected with pTP-Luc1 (55.5\%, $100 \mathrm{nM}$ mithramycin; 59.2\%, $300 \mathrm{nM}$ mithramycin), whereas promoter activity was measured at $41.8 \%$ in RA FLSs transfected with pGLS/TP I, relative to those transfected with pTP-Luc1. The observed inhibition was accelerated following treatment with mithramycin (38.2\%, 100 nM mithramycin; 35.1\%, 300 nM mithramycin) in RA FLSs transfected with pGLS/TP I. The promoter activity of pGLS/TP II and pGLS/TP III was largely inhibited with or without mithramycin.

\section{Analysis of the gliostatin/thymidine phosphorylase promoter by using a chromatin immunoprecipitation assay}

We performed a ChIP assay to confirm Sp1 binding to the promoter and examined the inhibitory effect of mithramycin on GLS gene expression. Sp1 was shown to bind to the furthest upstream Sp1-binding site of the GLS/TP promoter fragment (1,243 bp). Treatment with mithramycin suppressed binding at this site (Figure $2 \mathrm{~b}$ ). No amplification band was observed by using the nonspecific rabbit IgG, indicating the specificity of the DNA immunoprecipitation and ChIP assays.

\section{Nuclear accumulation of Sp1 in response to TNF- $\alpha$ and mithramycin}

To examine whether the nuclear localization of Sp1 changed following treatment with TNF- $\alpha$ or mithramycin, we prepared nuclear extracts from FLSs treated with or without $300 \mathrm{nM}$ mithramycin for 30 minutes, further incubated with $1 \mathrm{ng} / \mathrm{mL}$ TNF- $\alpha$ for 24 hours, and then subjected to immunoblotting with anti-Sp1, anti-lamin C, and anti- $\alpha$-tubulin antibodies. TNF- $\alpha$ treatment led to a remarkable accumulation of $\mathrm{Sp} 1$ in nuclear extracts, which was inhibited by treatment with mithramycin (Figure 3). The nuclear extracts were stained by the antilamin $\mathrm{C}$ antibody as a nuclear lamin marker but not by the anti- $\alpha$-tubulin antibody as a cytoplasmic marker.

\section{Inhibition of gliostatin expression by RNA interference}

To investigate the direct effect of Sp1 on GLS expression, we employed an siRNA against $\mathrm{Sp} 1$ for as an approach to inhibit GLS expression. The efficiency and specificity of siRNA gene knockdown of Sp1 were determined by Western blotting for Sp1 expression. Sp1 siRNA suppressed the $\mathrm{Sp} 1$ protein expression (Figure 4a). Sp1 siRNA
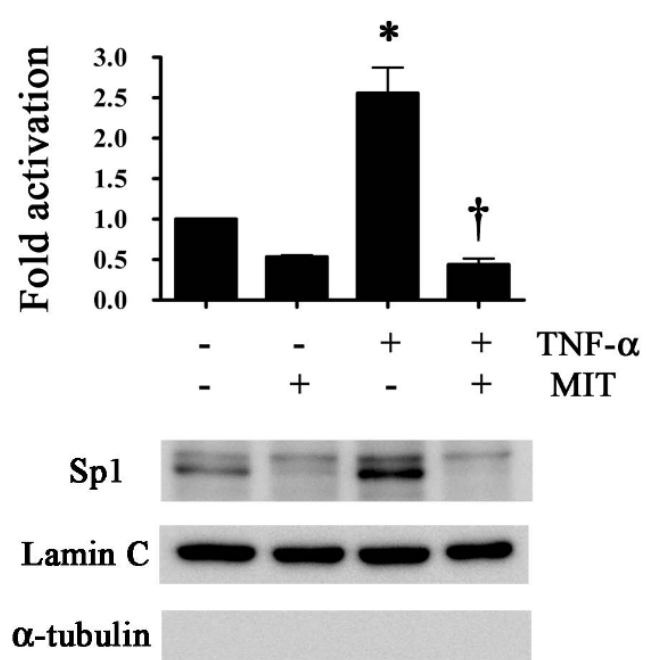

Figure 3 Effect of tumor necrosis factor-alpha (TNF- $\alpha$ ) and mithramycin on Sp1 protein expression in fibroblast-like synoviocyte nuclei. Fibroblast-like synoviocytes were cultured to confluence in the presence or absence of $300 \mathrm{nM}$ mithramycin for 30 minutes and then further incubated with or without TNF- $\alpha$ (1 $\mathrm{ng} / \mathrm{mL}$ ) for 24 hours. Nuclear extracts were processed for immunoblotting with an anti-Sp1 antibody. Anti-lamin C and anti- $\alpha$ tubulin immunoblotting were included to assess the purities of nuclear and cytoplasmic fractions, respectively. Results are presented as mean \pm standard error of the mean of five determinations. Statistical significance compared with controls was calculated by using the Mann-Whitney $U$ test: compared with controls ${ }^{*} P<0.05$; compared with samples with TNF- $\alpha$ alone ${ }^{\dagger} P<0.01$. MIT, mithramycin

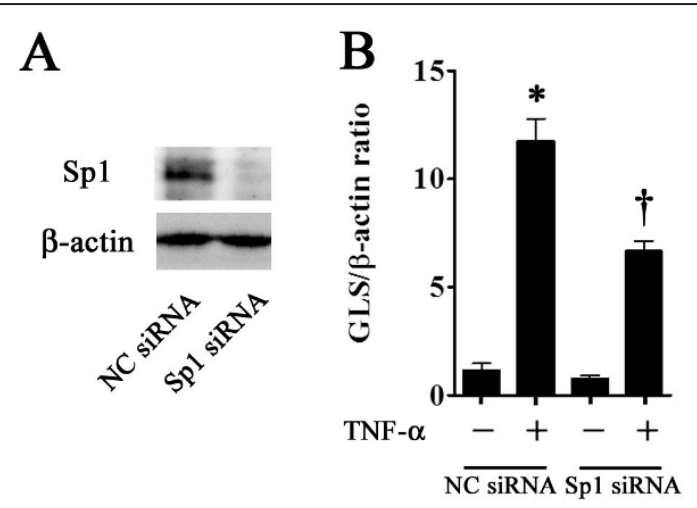

Figure 4 Effect of Sp1 RNA interference on gliostatin (GLS) expression. Western blotting analysis shows that Sp1 small interfering RNA (siRNA) (20 nM) transfection for 48 hours strikingly blocked Sp1 expression compared with negative control (NC) siRNA (20 nM) transfection (A). After Sp1 or NC siRNA transfection for 24 hours, cells were treated with tumor necrosis factor-alpha (TNF- $\alpha$ ) (1 $\mathrm{ng} / \mathrm{mL}$ ) for 24 hours. GLS mRNA expression levels are presented as mean \pm standard error of the mean of five determinations (B). GLS mRNA levels are represented relative to $\beta$-actin. Statistical significance was calculated by using the Mann-Whitney $U$ test: compared with NC siRNA samples * $P<0.01$; compared with NC siRNA samples with TNF- $\alpha{ }^{\dagger} p<0.01$. 
reduced TNF- $\alpha$-induced GLS gene expression by $56.7 \%$ at 48 hours post-transfection (Figure $4 \mathrm{~b}$ ).

\section{Effects of mithramycin on gliostatin production stimulated by TNF- $\alpha$ in cultured fibroblast-like synoviocytes}

FLSs were treated in the presence or absence of 10 to $300 \mathrm{nM}$ mithramycin for 30 minutes and then further incubated with $1 \mathrm{ng} / \mathrm{mL}$ TNF- $\alpha$ for 24 hours. GLS mRNA (Figure $5 \mathrm{a}$ ) and protein (Figure $5 \mathrm{~b}$ ) levels were significantly induced by treatment with TNF- $\alpha$ alone (11.3-fold and 2.1-fold compared with the control, respectively), and these inductions were suppressed by mithramycin treatment in a dose-dependent manner. GLS was not induced by treatment with mithramycin alone. We confirmed the non-toxic concentration at least 48 hours after incubation with 10 to $300 \mathrm{nM}$ mithramycin and $1 \mathrm{ng} / \mathrm{mL}$ TNF- $\alpha$ by using WST-8 assays (Cell Counting Kit-8; Dojindo Laboratories, Kumamoto, Japan) (data not shown). GLS mRNA expression increased in response to TNF- $\alpha$ (1 ng/ $\mathrm{mL}$ ) and reached a maximum at 24 hours (21.9-fold compared with the level at 0 hours) (Figure $5 \mathrm{c}$ ). GLS protein expression increased in response to TNF- $\alpha$ and continued to rise until at least 48 hours after treatment (5.6-fold
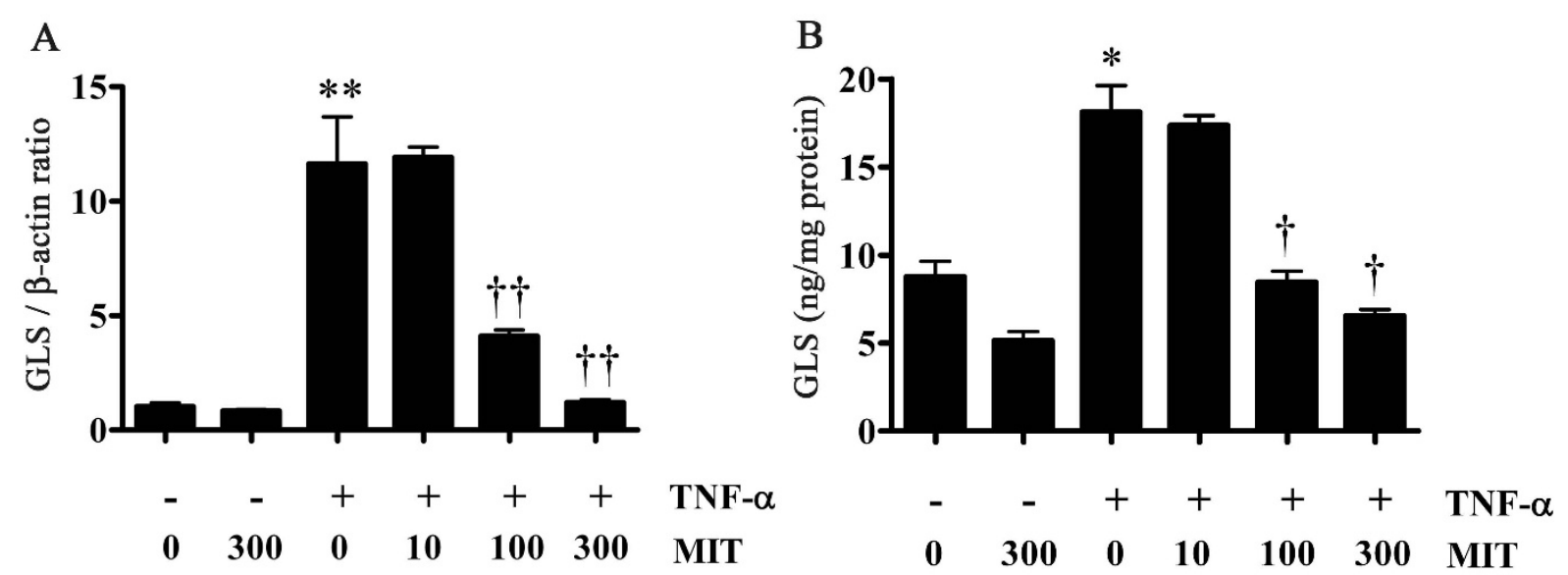

C

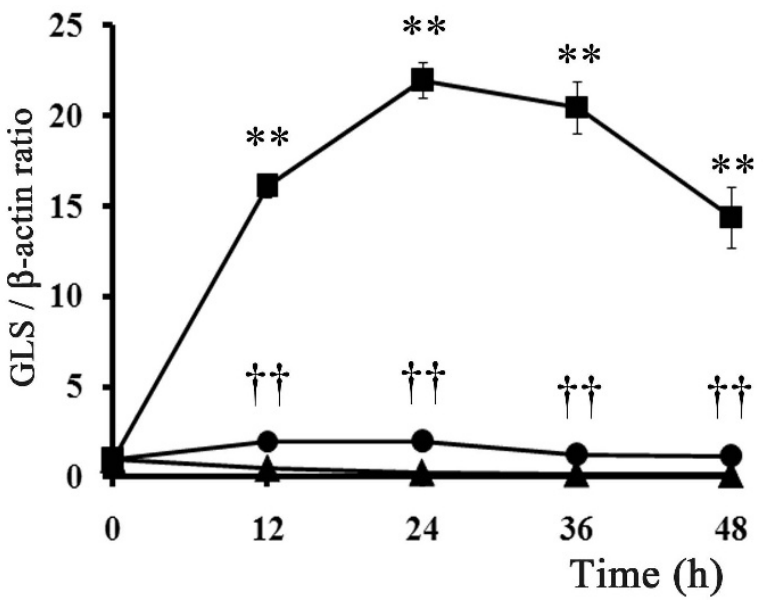

$\mathrm{D}$

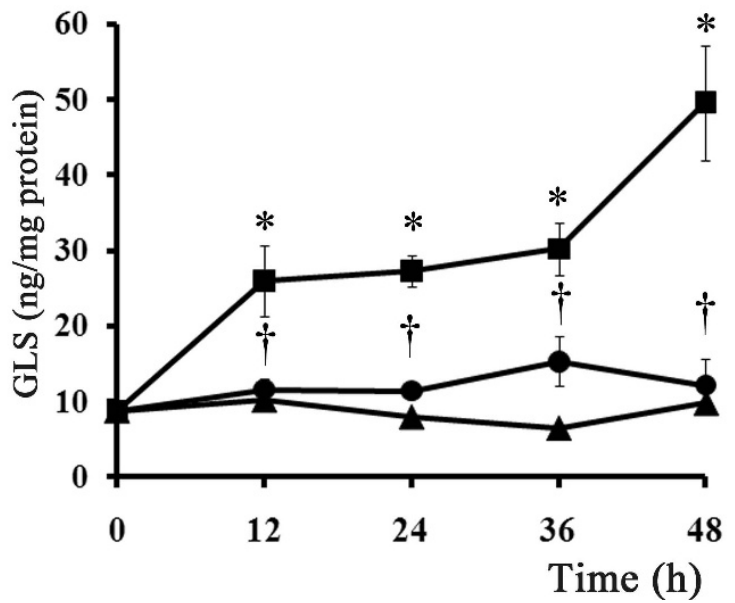

Figure 5 Mithramycin suppression of tumor necrosis factor-alpha (TNF- $\alpha$ )-induced gliostatin (GLS) expression in fibroblast-like synoviocytes (FLSs). Confluent FLSs were incubated in the presence or absence of 10 to $300 \mathrm{nM}$ mithramycin for 30 minutes and then with TNF- $\alpha$ for 24 hours. GLS gene expression levels are represented relative to $\beta$-actin (A). Immunoreactive GLS was determined by enzyme immunoassay (B). Results are presented as mean \pm standard error of the mean (SEM) of four determinations. Confluent cells were incubated in the presence (closed circle) or absence (closed square) of $300 \mathrm{nM}$ mithramycin for 30 minutes and then with TNF- $\alpha$ as indicated. Control FLSs were cultured without TNF- $\alpha$ (closed triangle). GLS mRNA (C) and protein (D) expression levels are presented as mean \pm SEM of four determinations. Statistical significance was calculated by using the Mann-Whitney $U$ test: compared with controls ${ }^{*} P<0.05,{ }^{* *} P<0.01$; compared with samples with TNF- $\alpha$ alone ${ }^{\dagger} p<0.05,{ }^{\dagger+} p<0.01$. MIT, mithramycin. 
compared with the level at 0 hours) (Figure $5 \mathrm{~d}$ ). These increases in GLS mRNA and protein were significantly suppressed by $300 \mathrm{nM}$ mithramycin treatment. To confirm whether TNF- $\alpha$ directly regulates GLS expression, FLSs were pre-treated with the protein synthesis inhibitor, cycloheximide. TNF- $\alpha$-induced GLS mRNA production significantly decreased in a dose-dependent manner with treatment of cycloheximide (Additional file 1).

FLSs were cultured to confluence in the presence or absence of $300 \mathrm{nM}$ mithramycin for 30 minutes, followed by further incubation with or without $1 \mathrm{ng} / \mathrm{mL}$ TNF- $\alpha$ for 24 hours. We observed no morphological change in FLSs during immunocytochemical staining. FLSs were immunostained with GLS antibody (red). Staining was weakly diffuse in the cytoplasm of FLSs that had not undergone treatment (Figure 6a). Treatment with mithramycin alone had no effect on GLS staining. The expression of GLS protein was significantly induced by treatment with TNF- $\alpha$ alone (1.5-fold compared with the control). This induction was significantly suppressed by mithramycin treatment (0.6-fold compared with the sample induced by TNF- $\alpha$ alone) (Figure 6b).

\section{Discussion}

TNF- $\alpha$ has been identified as a crucial cytokine in the pathogenesis of RA [30,31] and is involved in the activation of the nuclear factor-kappa-B (NF- $\kappa \mathrm{B})$ transcription factor $[32,33]$. In the present study, no NF- $\kappa \mathrm{B}$-binding sites were identified within the upstream GLS/TP promoter examined. It is therefore unlikely that TNF- $\alpha$ directly modulates transcriptional GLS regulation through binding the GLS/TP promoter. To determine the principal elements in the GLS/TP promoter which are relevant to GLS expression, we constructed a series of deletion mutant plasmids. Treatment with mithramycin inhibited GLS/TP promoter activity, confirming the potential for GLS production through Sp1 binding in FLSs.

Goto and colleagues [19] reported that interferongamma (IFN- $\gamma$ ) induced the expression of TP through ISRE and gamma-activated sequence in human macrophages. In the present study, the promoter activity was not regulated by IFN- $\gamma$ in FLSs (data not shown); however, this discrepancy could be explained by differences in the cellular properties of macrophages and FLSs. In addition, luciferase and ChIP assays showed that the Sp1-binding

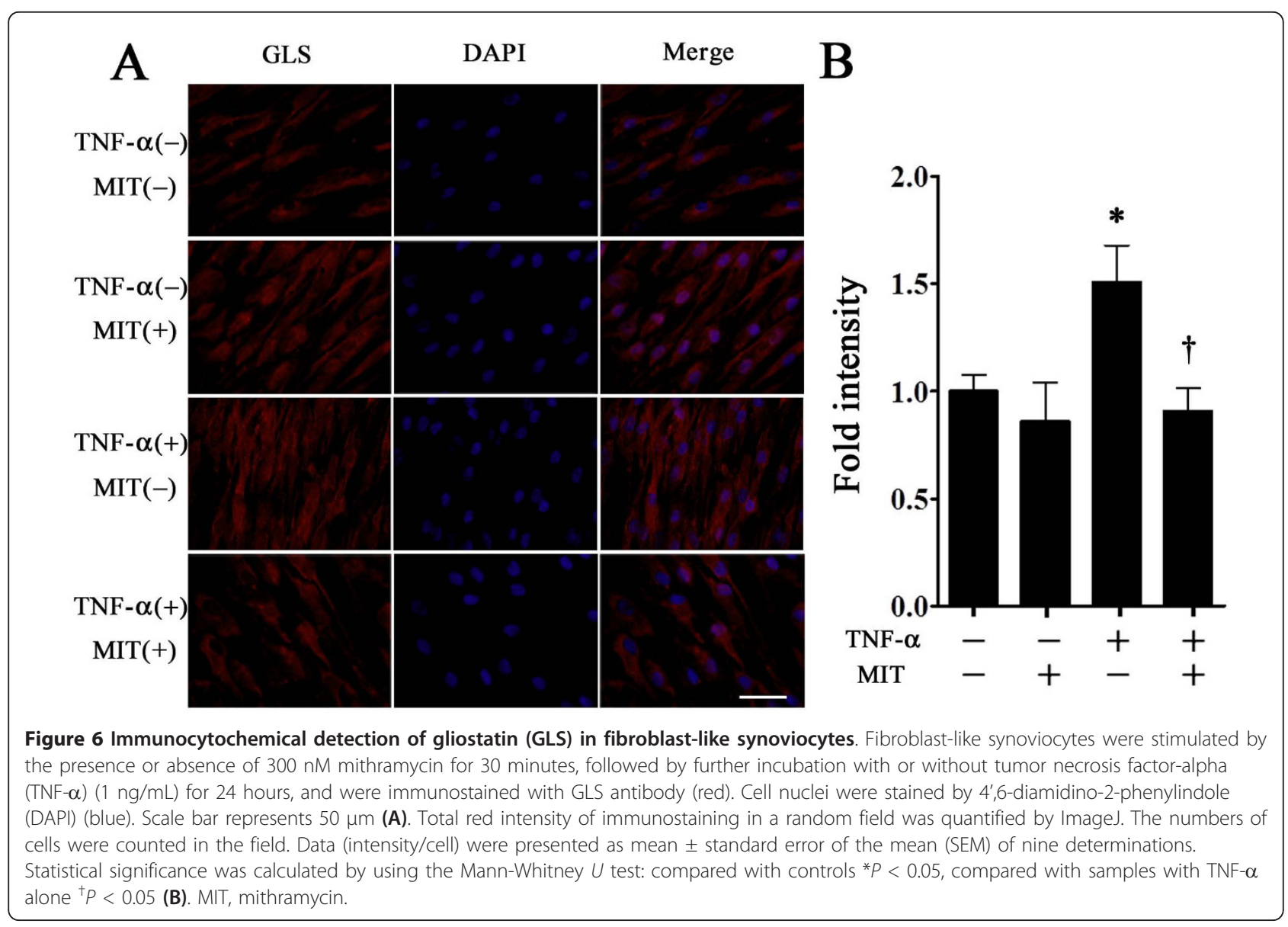


sites played an important role in regulating the promoter activity of the GLS gene and mithramycin exactly behaved as an Sp1 inhibitor. Other reports suggested that activated Sp1 is transported into the nucleus [34,35]; this was supported by our analysis of FLS nuclear fractions by using Western blotting, which revealed a remarkable accumulation of Sp1 in the nuclei following TNF- $\alpha$ treatment that was inhibited by treatment with mithramycin. We further investigated whether Sp1 directly regulated expression of GLS. We used RNA interference to detect the effects of Sp1 depletion on GLS expression at the mRNA levels.

We confirmed that TNF- $\alpha$-induced GLS mRNA and protein production were inhibited by mithramycin in a dose-dependent manner. Our immunocytochemical studies revealed that GLS was stained weakly and diffusely in FLS cytoplasm that had not undergone treatment. The intensity of GLS staining was increased by TNF- $\alpha$ treatment and suppressed by mithramycin at concentrations of 100 to $300 \mathrm{nM}$. These concentrations did not affect cell viability, as measured by a WST- 8 assay, and an in vivo study demonstrated that leukemia patients receiving a 2-hour continuous infusion of $25 \mu \mathrm{g} / \mathrm{kg}$ mithramycin did not exceed plasma levels of 300 to $350 \mathrm{nM}$ [36].

The protein synthesis inhibitor cycloheximide significantly decreased TNF- $\alpha$-induced GLS mRNA production in a dose-dependent manner. GLS gene transcription might require de novo protein synthesis in FLSs stimulated by TNF- $\alpha$, although the key protein involved remains to be identified.

In the pathogenesis of RA, we reported that GLS increased the expression of VEGF mRNA and protein in FLSs [14]. As angiogenesis is necessary for the perpetuation of inflammation, inhibition of angiogenic factors such as GLS and VEGF could provide a means to suppress the inflammatory cascade in RA synovitis [37]. We also reported that GLS induced the expression of matrix metalloproteinase (MMP)-1 and MMP-3 and GLS itself in FLSs [16]. The MMP family of proteins, including MMP-1, MMP-3, and MMP-13, plays a crucial role in excessive cartilage degradation in RA $[38,39]$. Other reports indicated that the gene expression levels of VEGF in fibroblasts [40,41] and of MMPs in articular chondrocytes [42] were closely related to that of Sp1. It was suggested, based on these findings, that an Sp1 inhibitor could be effective in reducing RA disease activity.

\section{Conclusions}

The present study indicates that expression of the GLS gene is mediated, in part, through the transcription factor Sp1. Our data suggest that the beneficial effects of mithramycin in RA might be at least partly due to antiangiogenic and anti-arthritogenic activity involving the downregulation of GLS. Mithramycin is therefore a promising candidate anti-rheumatic drug.

\section{Additional material}

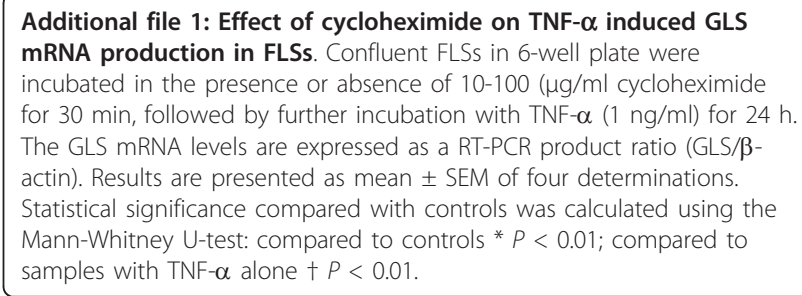

\section{Abbreviations}

bp: base pair; ChIP: chromatin immunoprecipitation; FLS: fibroblast-like synoviocyte; GLS: gliostatin; IFN- $\gamma$ : interferon-gamma; IL: interleukin; ISRE: interferon-stimulated response element; MMP: matrix metalloproteinase; NFKB: nuclear factor-kappa-B; PBS: phosphate-buffered saline; PCR: polymerase chain reaction; RA: rheumatoid arthritis; RT: reverse transcription; RT-PCR: reverse transcription-polymerase chain reaction; siRNA: small interfering RNA; TBS-T: Tris-buffered saline containing 0.1\% Tween 20; TNF-a: tumor necrosis factor-alpha; TP: thymidine phosphorylase; VEGF: vascular endothelial growth factor.

\section{Acknowledgements}

This research was supported by a Grant-in-Aid for Scientific Research (C) (23592225) from the Japan Society for the Promotion of Science. We thank Mieko Suzuki for her excellent technical assistance. We thank Mayumi Ono for the gift of the GLS/TP promoter fragment.

\section{Author details}

${ }^{1}$ Department of Orthopedic Surgery, Nagoya City University Graduate School of Medical Sciences, 1 Kawasumi, Mizuho-cho, MuzuhoMizuho-ku, Nagoya, 467-8601, Japan. ${ }^{2}$ Department of Molecular Neurobiology, Nagoya City University Graduate School of Medical Sciences, Mizuho-Ku, 1 Kawasumi, Mizuho-cho, MuzuhoMizuho-ku, Nagoya, 467-8601, Japan.

\section{Authors' contributions}

$\mathrm{Kl}$ and KK performed all the experiments, data analysis, and drafting of the manuscript. TY and MN participated in the interpretation of the data and performed the statistical analysis. MA and KA conceived of the study, participated in its design and coordination, and helped to draft the manuscript. YW-N conceived this study, provided financial support, designed experiments, interpreted the data, and drafted the manuscript. TO carried out administrative and financial support and helped to draft the manuscript. All authors read and approved the final manuscript.

\section{Competing interests}

The authors declare that they have no competing interests.

Received: 16 November 2011 Revised: 1 April 2012

Accepted: 25 April 2012 Published: 25 April 2012

\section{References}

1. Arend WP, Dayer JM: Cytokines and cytokine inhibitors or antagonists in rheumatoid arthritis. Arthritis Rheum 1990, 33:305-315.

2. Arend WP, Dayer JM: Inhibition of the production and effects of interleukin-1 and tumor necrosis factor a in rheumatoid arthritis. Arthritis Rheum 1995, 38:151-160.

3. Choy EHS, Panayi GS: Cytokine pathways and joint inflammation in rheumatoid arthritis. N Engl J Med 2001, 344:907-916.

4. Harada M, Mitsuyama K, Yoshida H, Sakisaka S, Taniguchi E, Kawaguchi T, Ariyoshi M, Saiki T, Sakamoto M, Nagata K, Sata M, Matsuo K, Tanikawa K: Vascular endothelial growth factor in patients with rheumatoid arthritis. Scand J Rheumatol 1998, 27:377-380.

5. Lee SS, Joo YS, Kim WU, Min DJ, Min JK, Park SH, Cho CS, Kim HY: Vascular endothelial growth factor levels in the serum and synovial fluid of patients with rheumatoid arthritis. Clin Exp Rheumatol 2001, 19:321-324. 
6. Asai K, Hirano T, Matsukawa K, Kusada J, Takeuchi M, Otsuka T, Matsui N, Kato T: High concentration of immunoreactive gliostatin/platelet-derived endothelial cell growth factor in synovial fluid and serum of rheumatoid arthritis. Clin Chim Acta 1993, 218:1-4.

7. Takeuchi M, Otsuka T, Matsui N, Asai K, Hirano T, Moriyama A, Isobe I, Eksioglu YZ, Matsukawa K, Kato T, Tada T: Aberrant production of gliostatin/platelet-derived endothelial cell growth factor in rheumatoid arthritis. Arthritis Rheum 1994, 37:662-672.

8. Asai K, Nakanishi K, Isobe I, Eksioglu YZ, Hirano A, Hama K, Miyamoto T, Kato T: Neurotrophic action of gliostatin on cortical neurons: identity of gliostatin and platelet-derived endothelial cell growth factor. J Biol Chem 1992, 267:20311-20316.

9. Furukawa T, Yoshimura A, Sumizawa T, Haraguchi M, Akiyama S, Fukui K, Ishizawa M, Yamada Y: Angiogenic factor. Nature 1992, 356:668.

10. Moghaddam A, Zhang H-T, Fan T-PF, Hu DE, Lees VC, Turley H, Fox SB, Gatter KC, Harris AL, Bicknell R: Thymidine phosphorylase is angiogenic and promotes tumor growth. Proc Natl Acad Sci USA 1995, 92:998-1002.

11. Miyadera K, Sumizawa T, Haraguchi M, Yoshida H, Konstanty W, Yamada $Y$, Akiyama S: Role of thymidine phosphorylase activity in the angiogenic effect of platelet-derived endothelial cell growth factor/thymidine phosphorylase. Cancer Res 1995, 55:1687-1690.

12. Asai K, Hirano T, Kaneko S, Moriyama A, Nakanishi K, Isobe I, Eksioglu YZ, Kato T: A novel glial growth inhibitory factor, gliostatin, derived from neurofibroma. J Neurochem 1992, 59:307-317.

13. Ueki T, Nakanishi K, Asai K, Okouchi Y, Isobe I, Eksioglu YZ, Kato T, Kohno K: Neurotrophic action of gliostatin on cocultured neuron with glial cells. Brain Res 1993, 622:299-302.

14. Tanikawa T, Waguri-Nagaya Y, Kusabe T, Aoyama M, Asai K, Otsuka T: Gliostatin/thymidine phosphorylase-regulated vascular endothelial growth-factor production in human fibroblast-like synoviocytes. Rheumatol Int 2007, 27:553-559.

15. Waguri Y, Otsuka T, Sugimura I, Matsui N, Asai K, Moriyama A, Kato T: Gliostatin/platelet-derived endothelial cell growth factor as a clinical marker of rheumatoid arthritis and its regulation in fibroblast like synoviocytes. Br J Rheumatol 1997, 36:315-321.

16. Muro H, Waguri-Nagaya $Y$, Mukofujiwara $Y$, Iwahashi T, Otsuka T, Matsui N, Moriyama A, Asai K, Kato T: Autocrine induction of gliostatin/plateletderived endothelial cell growth factor (GLS/PD-ECGF) and GLS-induced expression of matrix metalloproteinases in rheumatoid arthritis synoviocytes. Rheumatol 1999, 38:1195-1202.

17. Waguri-Nagaya Y, Otsuka T, Sugimura I, Matsui N, Asai K, Nakajima K, Tada T, Akiyama S, Kato T: Synovial inflammation and hyperplasia induced by gliostatin/platelet-derived endothelial cell growth factor in rabbit knees. Rheumatol Int 2000, 20:13-19.

18. Black AR, Black JD, Azizkhan-Clifford J: Sp1 and kruppel-like factor family of transcription factors in cell growth regulation and cancer. J Cell Physiol 2001, 188:143-160.

19. Goto H, Kohno K, Sone S, Akiyama S, Kuwano M, Ono M: Interferon gamma-dependent induction of thymidine phosphorylase/plateletderived endothelial growth factor through gamma-activated sequencelike element in human macrophages. Cancer Res 2001, 61:469-473.

20. Zojer N, Keck AV, Pecherstorfer M: Comparative tolerability of drug therapies for hypercalcaemia of malignancy. Drug Saf 1999, 21:389-406.

21. Kennedy BJ, Torkelson JL: Long-term follow-up of stage III testicular carcinoma treated with mithramycin (plicamycin). Med Pediatr Oncol 1995, 24:327-328.

22. Blume SW, Snyder RC, Ray R, Thomas S, Koller CA, Miller DM: Mithramycin inhibits SP1 binding and selectively inhibits transcriptional activity of the dihydrofolate reductase gene in vitro and in vivo. J Clin Invest 1991, 88:1613-1621.

23. Arnett FC, Edworthy SM, Bloch DA, McShane DJ, Fries JF, Cooper NS, Healey LA, Kaplan SR, Liang MH, Luthra HS, Medsger TA, Mitchell DM, Neustadt DH, Pinals RS, Schaller JG, Sharp JT, Wilder RL, Hunder GG: The American Rheumatism association 1987 revised criteria for the classification of rheumatoid arthritis. Arthritis Rheum 1988, 31:315-324.

24. Kusabe T, Waguri-Nagaya Y, Tanikawa T, Aoyama M, Fukuoka M, Kobayashi M, Otsuka T, Asai K: The inhibitory effect of disease-modifying anti-rheumatic drugs and steroids on gliostatin/platelet-derived endothelial cell growth factor production in human fibroblast-like synoviocytes. Rheumatol Int 2005, 25:625-630.
25. Yamagami T, Waguri-Nagaya Y, Ikuta K, Aoyama M, Asai K, Otsuka T: FK506 inhibition of gliostatin/thymidine phosphorylase production induced by tumor necrosis factor- $a$ in rheumatoid fibroblast-like synoviocytes. Rheumatol Int 2011, 31:903-909.

26. Nagahara M, Waguri-Nagaya Y, Yamagami T, Aoyama M, Tada T, Inoue K, Asai $K$, Otsuka T: TNF-a induced aquaporin 9 in synoviocytes from patients with OA and RA. Rheumatol (Oxford) 2010, 49:898-906.

27. Tsuchiya A, Imai K, Asamitsu K, Waguri-Nagaya Y, Otsuka T, Okamoto T: Inhibition of inflammatory cytokine production from rheumatoid synovial fibroblasts by a novel kappaB kinase inhibitor. J Pharmacol Exp Ther 2010, 333:236-243.

28. ImageJ, Image Processing and Analysis in Java. [http://rsbweb.nih.gov/ij/].

29. Hirano T, Asai K, Matsukawa K, Kato T, Takeuchi M, Yonezawa M, Otsuka T, Matsui N: Establishment of enzyme immunoassay system for gliostatin/ platelet-derived endothelial cell growth factor (PD-ECGF). Biochim Biophys Acta 1993, 1176:299-304.

30. Mclnnes IB, Schett G: Cytokines in the pathogenesis of rheumatoid arthritis. Nat Rev Immunol 2007, 7:429-442.

31. Firestein GS: Evolving concepts of rheumatoid arthritis. Nature 2003, 423:356-361.

32. Feldmann M: Pathogenesis of arthritis: recent research progress. Nat Immunol 2001, 2:771-773.

33. Okamoto T: The epigenetic alteration of synovial cell gene expression in rheumatoid arthritis and the roles of nuclear factor kappaB and Notch signaling pathways. Mod Rheumatol 2005, 15:79-86.

34. Ito T, Kitamura H, Uwatoko C, Azumano M, Itoh K, Kuwahara J: Interaction of Sp1 zinc finger with transport factor in the nuclear localization of transcription factor Sp1. Biochem Biophys Res Commun 2010, 403:161-166.

35. Kuwahara J, Watanabe $Y$, Kayasuga $T$, Ito K: Zn finger and nuclear localization of transcription factor Sp1. Nucleic Acids Symp Ser 2000, 44:265-266.

36. Fang K, Koller CA, Brown N, Covington W, Lin JR, Ho DH: Determination of plicamycin in plasma by radioimmunoassay. Ther Drug Monit 1992, 14:255-260.

37. Colville-Nash PR, Scott DL: Angiogenesis and rheumatoid arthritis: pathogenicand therapeutic implications. Ann Rheum Dis 1992, 51:919-925.

38. Kobayashi A, Naito S, Enomoto H, Shiomoi T, Kimura T, Obata K, Inoue K, Okada Y: Serum levels of matrix metalloproteinase 3 (stromelysin 1) for monitoring synovitis in rheumatoid arthritis. Arch Pathol Lab Med 2007, 131:563-570.

39. Lindy $O$, Konttinen $Y T$, Sorsa T, Ding Y, Santavirta S, Ceponis A, LópezOtín C: Matrix metalloproteinase 13 (collagenase 3 ) in human rheumatoid synovium. Arthritis Rheum 1997, 40:1391-1399.

40. Milanini J, Vinals F, Pouyssegur J, Pages G: p42/p44 MAP kinase module plays a key role in the transcriptional regulation of the vascular endothelial growth factor gene in fibroblasts. J Biol Chem 1998, 273:18165-18172.

41. Milanini-Monqiat J, Pouyssequr J, Pages G: Identification of two Sp1 phosphorylation sites for p42/p44 mitogen-activated protein kinases: their implication in vascular endothelial growth factor gene transcription. J Biol Chem 2002, 277:20631-20639.

42. Liacini A, Sylvester J, Li WQ, Zafarullah M: Mithramycin downregulates proinflammatory cytokine-induced matrix metalloproteinase gene expression in articular chondrocytes. Arthritis Res Ther 2005, 7:R777-783.

doi:10.1186/ar3811

Cite this article as: Ikuta et al:: The Sp1 transcription factor is essential for the expression of gliostatin/thymidine phosphorylase in rheumatoid fibroblast-like synoviocytes. Arthritis Research \& Therapy 2012 14:R87. 